\title{
Impact of oncologic pathology (OP) in the evolution of severe sepsis (SS) in the critically ill patients (CIP)
}

\author{
J Ruiz Moreno ${ }^{1 *}$, E González Marín ${ }^{1}$, MJ Esteve Paños ${ }^{1}$, R Corcuera Romero de la Devesa ${ }^{1}$, M Moral Guiteras ${ }^{1}$, \\ M Juliá Amill', N Suárez Álvarez', N Conesa Folch¹, F Baigorri González', A Artigas Raventós
}

From ESICM LIVES 2015

Berlin, Germany. 3-7 October 2015

\section{Intr}

It is considered that the severity of septic CIPs is higher than the overall CIPs requiring ICU admission. Nevertheless, the impact of the OP over the severity of the SS perhaps has not been sufficiently analyzed and evaluated.

\section{Objectives}

To evaluate the impact of the OP in the evolution of the SS of the CIPs.

\section{Methods}

- Study: prospective, analytical, longitudinal, and observational

. Period: January 1-2011 / June 30-2014 (42 months)

- SETTING. Medical/Surgical ICU

- Population: 2559 CIPs admitted consecutively to the ICU; sample: 484 CIPs with SS.
- Exclusión criteria: CIPs < 16 y., major burn CIPs, incomplete clinical documentation, and voluntary discharge.

- Variables analyzed:

a) Age

b) Hospital mortality

c) Case - mix: metabolic acidosis, total parenteral nutrition, intra-abdominal pressure (IAP), blood products, cultures, cardiac output, renal replacement therapy (RRT), advanced life support (ALS), FGC, FBC,

e) Organ dysfunction: SOFA and LODS

f) Limitation of life support (LLS).

- Statistical analysis: Ji squared and contrast of means (Student's t)

- Limitations of the study: absence of critically burned patients and pediatric CIPs

Table 1

\begin{tabular}{|c|c|c|c|c|c|c|c|c|c|}
\hline & Global & $\%$ & SS & $\%$ & SS with OP & $\%$ & SS witout OP & $\%$ & $p$ value \\
\hline $\mathrm{N}$ & 2559 & 100 & 484 & 18,9 & 130 & 26,9 & 354 & 73,1 & \\
\hline Age & 65,88 & 16,7 & 73,5 & 13,1 & 73,18 & 11,4 & 73,64 & 13,7 & NS \\
\hline Mortality & 182 & 7,1 & 120 & 24,8 & 39 & 30,0 & 81 & 22,9 & NS \\
\hline RRT & 91 & 3,6 & 70 & 14,6 & 20 & 15,8 & 50 & 14,1 & NS \\
\hline TPN & 467 & 18,2 & 184 & 38,0 & 90 & 69,3 & 94 & 26,5 & 0,0001 \\
\hline IAP & 136 & 5,3 & 101 & 20,8 & 37 & 28,6 & 64 & 18,1 & 0,012 \\
\hline Metb acid & 955 & 37,3 & 368 & 76,0 & 113 & 86,9113 & 255 & 72,0 & 0,0006 \\
\hline
\end{tabular}


Table 2

\begin{tabular}{|c|c|c|c|c|c|c|c|c|c|}
\hline & Global & $\%$ & SS & $\%$ & SS with OP & $\%$ & SS witout OP & $\%$ & $p$ value \\
\hline Blood products & 500 & 19,5 & 216 & 44,6 & 83 & 63,8 & 133 & 37,6 & 0,0001 NS NS \\
\hline Cultures & 689 & 26,9 & 456 & 94,2 & 119 & 91,5 & 337 & 95,2 & NS \\
\hline Pericardiocent. & 8 & 0,3 & 3 & 0,6 & 2 & 1,5 & 1 & 0,9 & NS \\
\hline ALS & 85 & 3,3 & 42 & 8,7 & 16 & 12,3 & 26 & 7,3 & 0,085 \\
\hline FGC & 54 & 2,1 & 28 & 5,8 & 8 & 6,1 & 20 & 5,6 & NS \\
\hline$\overline{\mathrm{FBC}}$ & 61 & 2,3 & 47 & 9,7 & 12 & 9,2 & 35 & 9,9 & NS \\
\hline LLS & 220 & 8,6 & 122 & 25,2 & 41 & 31,5 & 81 & 22,9 & 0,0518 \\
\hline
\end{tabular}

\section{Results}

Global CIPs: 2559; sepsis CIPs: 484; non sepsis CIPs: 2075

SOFA: Global (2.70), septic CIPs (5,32), non-septic CIPs $(1,90)$

LODS: Global (1.37), septic CIPs $(2,78)$, non-septic CIPs $(0,94)$

See Tables 1 and 2.

\section{Conclusions}

1) The OP conditions not age or mortality of CIPs with SS.

2) Metabolic acidosis and the need of TPN, IAP and blood products are higher in the SS with OP.

3) Cultures, RRT, ALS, FGC, and FBC are applied equally in both groups.

4) The LLS is applied more in the SS with OP.

\section{Authors' details}

'QuirónSalud Hospital Universitario Sagrat Cor, Critical Care Department, Barcelona, Spain. ${ }^{2}$ Hospital de Clínicas de Sabadell \& QuirónSalud Hospital Universitario Sagrat Cor, Critical Care Department, Sabadell, Spain.

Published: 1 October 2015

\section{References}

1. Phillips R, Hancock B, Graham J, Bromham N, Jin H, Berendse S: Prevention and management of neutropenic sepsis in patients with cancer: summary of NICE guidance. BMJ 2012, 345:e5368.

2. Corcuera Romero de la Devesa R, Ruiz Moreno J, González Marín E, Esteve Paños MJ, Godayol Arias S, Conesa Folch N, Rinaudo Videla M, Artigas Raventós A: Evaluation of severity in critically ill patientes (CIPS) with sepsis. European Society of Intensive Care Medicine, 27th Annual Congres Barcelona, Spain; 2014, September.

3. Kaukonen KM, Bailey M, Suzuki S, Pilcher D, Bellomo R: Mortality Related to Severe Sepsis and Septic Shock Among Critically III Patients in Australia and New Zealand, 2000-2012. JAMA 2014, 311(13):1308-1316.

doi:10.1186/2197-425X-3-S1-A247

Cite this article as: Ruiz Moreno et al:: Impact of oncologic pathology (OP) in the evolution of severe sepsis (SS) in the critically ill patients (CIP).

Intensive Care Medicine Experimental 2015 3(Suppl 1):A247.

Submit your manuscript to a SpringerOpen ${ }^{\circ}$ journal and benefit from:

- Convenient online submission

- Rigorous peer review

- Immediate publication on acceptance

- Open access: articles freely available online

- High visibility within the field

- Retaining the copyright to your article

Submit your next manuscript at $>$ springeropen.com 